\title{
Current developments in endovascular therapy of peripheral vascular disease
}

\author{
Damianos G. Kokkinidis, Ehrin J. Armstrong \\ Division of Cardiology, Rocky Mountain Regional VA Medical Center, University of Colorado, Aurora, CO, USA \\ Correspondence to: Ehrin J. Armstrong, MD, MSc. 1600 North Wheeling Street, Aurora, CO 80045, USA. Email: ehrin.armstrong@gmail.com.
}

\begin{abstract}
More than 200 million people worldwide have peripheral artery disease (PAD) or its most severe manifestation, critical limb ischemia (CLI). While endovascular treatment has become first line therapy in most cases, a number of challenges remain for optimal treatment of femoropopliteal (FP) or infrapopliteal (IP) disease, especially when these lesions are severely calcified, chronic total occlusions (CTOs) or instent restenosis (ISR). Continued evolution of technologies has significantly improved the outcomes for endovascular treatment. A number of new devices are in the pipeline right now, including new paclitaxel eluting stents and balloons, intravascular lithotripsy to treat severely calcified lesions, adventitial delivery of anti-restenotic agents to limit restenosis rates, and percutaneous femoro-popliteal bypass.
\end{abstract}

Keywords: peripheral artery disease; femoropopliteal disease; infrapopliteal disease; below the knee arteries; chronic total occlusions (CTOs); emerging therapies; novel technologies; adventitial delivery; lithotripsy; drugeluting stents (DES); drug-coated balloons (DCBs); percutaneous bypass

Submitted Oct 18, 2019. Accepted for publication Dec 13, 2019.

doi: $10.21037 /$ jtd.2019.12.130

View this article at: http://dx.doi.org/10.21037/jtd.2019.12.130

\section{Introduction}

The estimated prevalence of peripheral artery disease (PAD) is close to 200 million (1). The most common presentation of PAD includes lifestyle limiting claudication $(1,2)$. A significant portion of patients with PAD develop rest pain or ulcers and subsequent need for amputation $(1,2)$. Critical limb ischemia (CLI) is particularly common in diabetics and in other patient groups with calcified arteries and is mainly encountered in infrapopliteal (IP) vessels and less commonly in the femoropopliteal (FP) artery, contrary to claudication which is most commonly caused by lesions in the FP artery $(3,4)$. Suprainguinal PAD in the absence of lesions lower in the arterial tree is associated primarily with claudication and rarely with CLI $(5,6)$.

In the past, PAD was treated with open surgical approaches but with new technologies, more and more peripheral interventions are performed with an endovascular first approach (2,7-11). However, both FP and IP lesions can be very challenging to treat with an endovascular approach (10-13). The FP artery is challenging in terms of sustainability of the endovascular interventions because of its unique anatomical characteristics including length and involvement in knee motion, making this segment vulnerable to torsion, resulting in low patency and high instent restenosis (ISR) rates (14-19). IP lesions also pose a number of technical challenges given that these vessels have small diameter and high calcification burden which makes endovascular interventions difficult to perform but also decreases long-term patency rates (20-22).

Continued evolution of technologies in recent years has significantly improved the outcomes for endovascular treatment of infrainguinal lesions, even for the most difficult FP and IP lesions (2). With this review article, we present the current development in endovascular interventions for these lesions.

\section{Novel drug coated balloons}

The concept behind paclitaxel use as a component of drugcoated balloons (DCBs) in peripheral arteries is based on its antirestenotic and hydrophobic, lipophilic properties. 
Table 1 Available drug-coated balloons in the United States

\begin{tabular}{lccccc}
\hline Company & Excipient & Diameter & Length & Nominal dose & Potential dose range \\
\hline Medtronic & Urea & $4-7 \mathrm{~mm}$ & $20-250 \mathrm{~mm}$ & $3.5 \mu \mathrm{g} / \mathrm{mm}^{2}$ & $1.1-17.0 \mathrm{mg}$ \\
Bard & Polysorbate, Sorbitol & $4-7 \mathrm{~mm}$ & $40-220 \mathrm{~mm}$ & $2 \mu \mathrm{m} / \mathrm{mm}^{2}$ & $1.0-9.7 \mathrm{mg}$ \\
Phillips & PEG 8000, lodine & $4-6 \mathrm{~mm}$ & $40-200 \mathrm{~mm}$ & $2 \mu \mathrm{m} / \mathrm{mm}^{2}$ & $1.1-4.7 \mathrm{mg}$ \\
Cook & None & $5-8 \mathrm{~mm}$ & $40-140 \mathrm{~mm}$ & $3 \mu \mathrm{g} / \mathrm{mm}^{2}$ & $0.2-1.3 \mathrm{mg}$ \\
\hline
\end{tabular}

Paclitaxel is merged with an excipient that is hydrophilic, allowing for delivery of the drug from the balloon surface to the artery $(17,23-27)$. The lipophilic properties of paclitaxel allows it to be absorbed by the artery wall and decrease the neointimal hyperplasia (26,27). More than ten different DCBs are currently available in Europe. On the other hand, three are FDA approved and available in the USA; Stellarex 0.035" DCB (Phillips), IN.PACT Admiral DCB (Medtronic, Dublin, Ireland) and the Lutonix 0.035" Drug Coated Balloon (Bard). The nominal dose of paclitaxel concentration is between $2-3.5 \mu \mathrm{g} / \mathrm{mm}^{2}$ and the diameter range of available balloons ranges from 4 to $7 \mathrm{~mm}$ (4-6 mm for the Stellarex $035 \mathrm{DCB})$. Table 1 presents the currently available drug eluting devices in the United States. DCBs have been shown to lead to improve outcomes compared to balloon angioplasty (BA) for FP interventions (23-25). There is no clear superiority compared to drugeluting stents (DES) but the avoidance of a metallic layer in the vessel is appealing especially for frequent restenosed vessels such as the FP segment $(17,28,29)$. DCBs can be also combined with orbital atherectomy for FP lesions or laser atherectomy for the treatment of FP-ISR lesions and the results from small studies appear promising (9,30-35). Contrary to FP lesions, DCB have been rarely used in iliac or common femoral arteries (36-38). DCBs have been also used for IP lesions but the results to date have not yet demonstrated superiority to BA (39-45).

DCBs and in general drug-eluting technologies were recently challenged since the publication of a study level meta-analysis by Katsanos et al. that found that the use of paclitaxel-coated devices for FP lesions increases the overall risk of death (46). Even though there was no difference after 1 year of follow-up among 4,663 patients treated with paclitaxel-coated $v s$. non-coated devices among 28 randomized controlled trials, the relative risk of all-cause mortality was increased by $68 \%$ after 2 -year and $93 \%$ after 5 -year of follow-up (46). The absolute risk difference was $3.5 \%$ at 2 -year and $7.2 \%$ at 5 -year, while the number- needed-to-harm was 29 patients at 2-year and 14 patients at 5 years.

Although this meta-analysis faced criticism for the fact that it was a study level meta-analysis (investigators did not have access to patient-level data), the signal that was detected for increased mortality in the paclitaxel arm had numerous consequences for paclitaxel eluting products (47-49). First, there was a safety review by the US and United Kingdom regulatory authorities $(50,51)$. Second, the FDA issued a letter to physician who participate in the care of patients with PAD regarding the potential dangers associated with their use, instructing physicians to report any potential adverse events (52-54). Third, within days of the publication of the meta-analysis, a number of trials of paclitaxel-eluting products including the BASIL-3 [testing DCBs, DES and BA with bail-out bare-metal stent (BMS) revascularization strategies for FP disease in United Kingdom], the Swedish Drug-elution Trial in Peripheral Arterial Disease (SWEDEPAD) 1 and SWEDEPAD 2 suspended enrollment of patients. SWEDEPAD 1 and 2 plan to enroll in total 3,800 patients with PAD and comparing revascularization strategies with and without DCBs and/or DES $(54,55)$. Fourth, the meta-analysis by Katsanos et al. faced significant criticism regarding its methodology including pooling study level data-patient level data was not available-not using a survival analysis method, and not accounting for patients who were lost to follow-up (24,56-59). Fifth, a number of studies examining similar populations, tried to confirm the findings of this patient level by meta-analysis $(60,61)$. Schneider et al. performed an individual patient level meta-analysis of patients treated with the IN.PACT Admiral paclitaxel DCB for the treatment of symptomatic FP PAD (60). In total, 1,980 patients (2 RCTs and 2 prospective single-arm studies) were included. The investigators did not find any differences in mortality between DCB and BA at 5 years and no correlation between varying levels of paclitaxel exposure and mortality (60). Subsequently an analysis was 
published using data from of all the hospitalizations among Centers for Medicare and Medicaid Services (CMS) fee-forservice beneficiaries from the Medicare Provider Analysis and Review (MedPAR) files from January 01, 2016, through December 31, 2016 (61). Patients treated with drug-coated devices had a lower all-cause mortality after 600 days of follow-up compared to patients treated without drug-coated devices ( $32.5 \%$ vs. $34.3 \%$, respectively; log-rank $\mathrm{P}=0.007$ ).

It should be noted that the above meta-analytic findings were based solely on first generation DCB and DES, and did not include newer devices that were either recently approved or under study. Long-term follow-up will be necessary to determine the association, if any, between these newer devices and the overall risk of mortality. For example, a recent patient-level meta-analysis of the Stellarex DCB (Philips Inc.) did not show any association between DCB use and mortality (62). Two additional DCBs, the Ranger DCB and Surmodics DCB, are also under clinical development.

\section{Ranger DCB}

The Ranger DCB (Boston Scientific Corporation) uses a proprietary TransPax ${ }^{\mathrm{TM}}$ coating system. A citrate ester excipient facilitates a novel hydrophobic form of paclitaxel and enables an improved deliverability, stability (potentially decreasing embolization risk), and efficacy, and a sustained release of paclitaxel (63-66).

In the Ranger ${ }^{\mathrm{TM}}$ SFA which was an RCT for FP lesions, 71 patients in total were enrolled in the DCB arm and 34 patients in the BA arm (2:1 design), without major differences between the two groups. Ranger led to improve 6 - and 12 -month TLR rate (6 months: $5.6 \%$ vs. $12 \%$ for BA, 12 months: $91.2 \%$ vs. $69.9 \%$ for BA), while also achieving an improved 12 -month primary patency rate (86.4\% vs. $56.5 \%$ for the BA group) $(64,66)$.

After this first RCT, the 12 -month results of the COMPARE-1 clinical trial were presented at LINC 2018 (Scheinert D, Leipzig Interventional Course, January 2018, Leipzing, Germany). The investigators performed a headto-head prospective randomized comparison of the Ranger DCB $v s$. the In.PACT DCB in native lesions with $>70 \%$ stenosis or occlusion of SFA or proximal popliteal segment in patients with Rutherford II, III and IV. Interestingly, the Ranger device has $33 \%$ less paclitaxel compared to the In.PACT DCB (2 vs. $\left.3 \mu \mathrm{g} / \mathrm{mm}^{2}\right)$. There were 150 patients
(74 patients were treated with the Ranger DCB and 76 patients were treated with the In.Pact DCB) who were enrolled in the phase 1 pilot study and the follow-up was scheduled for 6, 12 and 24 months (63). The two groups did not differ in the 1 -year patency rates $(84 \%$ for the Ranger DCB versus $89 \%$ for the In.Pact DCB). The phase 2 extension of the trial (up to 414 patients) is anticipated to confirm a noninferiority hypothesis (NCT02701543) and is anticipated to be completed by 2023 .

\section{Surmodics}

The SurVeil ${ }^{\circledR}$ DCB (Surmodics Inc) was studied in the PREVEIL early feasibility study (EFS) and the first results were presented in the Vascular Interventional Advances (VIVA) 2018 conference in Las Vegas (63). PREVEIL is a prospective, US, multi-center, single-arm trial at three different clinical sites for the treatment of native $\mathrm{FP}$ arteries (NCT02648620). In total, 13 patients were included and the average lesion length was $56 \mathrm{~mm}$. Median paclitaxel plasma concentration peaked immediately post-procedure $(\mathrm{Cmax} 1.07 \mathrm{ng} / \mathrm{mL}$ ) and was undetectable at 30 days. There were no TLR events and an improvement in Rutherford class, ABI and walking distance and speed was noticed after 1-year of follow-up. Pre-clinical data for the SurVeil DCB have shown that it can achieve an up to five times higher concentration of the drug in the target tissue, while the substance is evenly distributed and achieves a more durable drug effect while at the same time decreasing the incidence of downstream drug concentrations compared to control DCBs. After successfully finishing PREVEIL, Surmodics Inc has started the TRANSCEND trial which is a prospective, multi-center, single-blind, randomized, controlled, noninferiority clinical trial in 65 sites around the world (63). TRANSCEND temporarily stopped enrollment after the FDA letter on March $15^{\text {th }} 2019$ but resumed almost 1 month later after updating investigator communications, patient Informed Consent Forms (ICF), and data safety review and patient follow-up procedures. In total, 446 patients with FP disease were enrolled in a 1:1 fashion to treatment with either the SurVeil DCB or the IN.PACT Admiral DCB, and they will be followed for up to 5 years in total (NCT03241459). The primary outcome is 12 -month primary lesion patency and also the composite endpoint of death, amputation, and target vessel revascularization (TVR) (NCT03241459). 


\section{Novel drug eluting stents}

\section{DES for FP disease}

Past trials have shown that the use of a nitinol self-expanding stent instead of BA was associated with improved outcomes (67-69). However FP arteries continued to be a challenging segment for peripheral interventionalists $(18,19)$. The special anatomical characteristics of the FP segment increase the pressure applied to the FP axis and increase the risk for stent fracture or restenosis $(18,19,70-73)$. The development of the Zilver PTX (paclitaxel-eluting stent) by Cook Medical led to superior 2- and 5-year outcomes compared to BA for patients treated with this selfexpanding DES. Zilver PTX was also superior to BMS when compared to bail-out stenting options (46,74-76). Similarly with DCBs, DES were also under review by the FDA after the publication of the recent meta-analysis suggesting increased mortality risk with the drug-eluting devices in the FP region (46). A recent analysis was performed on the data that COOK Medical made publically available after the publication of the meta-analysis by Katsanos et al. and the FDA letter $(46,77,78)$. The investigators evaluated mortality in all patients treated with the DES regardless of the patients' original treatment assignments. Two treatment groups were analyzed and compared: DES $v s$. no DES (BA with or without BMS) (78). There was no difference in 5 -year mortality (19.1\% DES vs. $17.1 \%$ BA/BMS, $\mathrm{P}=0.60)$ (78). Neither treatment with Zilver PTX $(\mathrm{P}=0.46)$ nor paclitaxel dose $(\mathrm{P}=0.86)$ was associated with mortality (78). Another study examined patients with a diagnosis of PAD among the US Centers for Medicare \& Medicaid Services (CMS) Medicare Provider Analysis and Review files compared patients treated with DES vs. BMS for their peripheral artery lesions (79). Patients treated with DES vs. BMS had similar mortality through 4.1 years (51.7\% for DES vs. $50.1 \%$ for BMS; log-rank $\mathrm{P}=0.16$ ) (79).

\section{ELUVIA ${ }^{\mathrm{TM}}$ DES}

The Eluvia ${ }^{\mathrm{TM}}$ (Boston Scientific, Marlborough, MA, USA) stent uses the Innova ${ }^{\mathrm{TM}}$ self-expanding nitinol stent system platform based on a primer layer of poly n-butyl methacrylate (PBMA) and has a sustained drug release for more than a year $(80,81)$, while the results from the early studies showed that Eluvia can potentially lead to improve outcomes compared to BMS (80-83).

The MAJESTIC trial was a prospective, single-arm trial with 57 patients with FP lesions $<110 \mathrm{~mm}$ treated with Eluvia ${ }^{\mathrm{TM}}$. After 12 months of follow-up, only two patients underwent TLR while the 1-year primary patency rate was $96.4 \%$ (84). The subsequent IMPERIAL trial compared the Eluvia stent with the Zilver PTX stent on the basis that the prolonged paclitaxel elution with Eluvia may actually be helpful in preventing the FP segment restenosis after 1-year of follow-up. In total 409 patients were included (Eluvia: $\mathrm{n}=276$; Zilver PTX: $\mathrm{n}=133$ ) (85). The clinical follow-up was at 1, 6 and 12 months with plan to continue following these patients for up to 5 years. The primary efficacy endpoint was 12 -month primary patency as assessed at the 12-month follow-up visit with duplex ultrasound if the patient did not have a clinically driven TLR in the interim. The primary safety endpoint was a composite of any major adverse events including 1-month mortality, 12-month TLR and 12-month target limb loss. The Eluvia stent was shown to be non-inferior in both the efficacy and safety analysis (85), with higher 12-month primary patency $(87 \%$ vs. $82 \%$ ) with significantly lower number of stent thrombosis or TLR events in the Eluvia group compared to Zilver PTX group (85).

\section{DES for IP disease}

IP disease has high rates of CLI and thus limb salvage is one of the primary reasons for revascularization (86). However, IP lesions have unique characteristics in terms of higher calcification rates, smaller diameters, and poorer run-off (20-22), while historically IP artery patency rates were very low (87). Additionally endovascular technology for these vessels is less advanced compared to the above the knee arteries and fewer options have been available for many years (2). Even if endovascular treatment with BA can potentially offer significant advantages for these patients compared to open techniques given the multiple comorbidities patients with CLI usually have, the results were suboptimal in the past (88). Coronary DES have been evaluated for short IP lesions in prior RCTs, showing superior patency rates and lower TLR rates compared to BA or BMS (89-91). However, there were not significant differences in clinical improvement or amputation free survival (89-94). Even if the IDEAS trial showed that DES led to lower 6-month restenosis rates compared to DCB and can be theoretically eligible for longer IP lesions also, DES use in IP is current suggested only for focal lesions and mainly as a bail-out strategy (95). Notably, no coronary DES are specifically labeled for IP use in the US. 


\section{Novel drug-eluting stents-SAVAL DES}

The SAVAL trial is testing the Saval ${ }^{\mathrm{TM}}$ DES (Boston Scientific Corporation) for the treatment of IP lesions (NCT03551496). The Saval DES is self-expanding, coated with paclitaxel, and is longer compared to coronary DES (96). The first phase of this multicenter, randomized trial in a 2:1 fashion (DES vs. BA) trial will include in total 301 patients with CLI and IP lesions who will be enrolled in centers in Europe, Asia and the US (NCT03551496). The second phase will be a nonrandomized, single-arm study of 100 patients treated with the Saval ${ }^{\mathrm{TM}}$ DES BTK. For both of the phases, inclusion criteria include patients with CLI and Rutherford IV or V symptoms, $\leq 2$ IP lesions, reference vessel diameter of 2.5 to $3.75 \mathrm{~mm}$, total lesion length $\leq 70 \mathrm{~mm}$, and lesion location at least $4 \mathrm{~cm}$ above the ankle joint. All enrolled patients will have clinical and ultrasound follow-up after 1, 3, 6, 12 months and then annually for 3 years. The primary efficacy endpoint is the 6-month primary patency for the RCT, while the primary safety endpoint will be the freedom from 6-month major adverse limb events and postoperative death within 30-day after the index procedure. The primary purpose of the single arm second phase SAVAL trial is to evaluate the Saval stent for the safety endpoint of freedom from 12-month MALE and 1-month mortality (96).

\section{Adventitial drug delivery}

The migration of fibroblasts from the adventitia towards the intima plays an important role in the pathogenesis of restenosis after BA (97-102). The adventitia is the outer layer of the arteria wall and can offer a solid environment in order to achieve maximum drug concentration (97-100,102). Based on this concept, adventitial drug delivery is being investigated as a potential target in order to minimize restenosis rates and improve outcomes in endovascular interventions (2,97-102).

Dexamethasone has been examined as a potential agent that can be delivered in the adventitia. High dosages of dexamethasone delivered into the adventitia can have the potential to control the inflammation in the adventitia and stop the migration of fibroblasts to the intima by downregulating the production of pro-inflammatory molecules such as monocyte chemoattractive protein (MCP), tumor necrosis factor (TNF)-a, interleukin (IL)-10, matrix metalloproteinase (MMP)-9, and nuclear factor-kappalight-chain enhancer of activated B-cells (NF-kB) $(103,104)$.
Another advantage of delivery to the adventitia is that the drug is delivered directly to the target tissue rather than having to bypass other tissues including atherosclerotic plaque and calcium. With the use of the Bullfrog MicroInfusion Catheter (Mercator MedSystems, San Leandro, CA, USA), dexamethasone injection directly to the FP artery was examined. When the balloon of the catheter is inflated, a needle directed towards the vessel wall penetrates the vessel wall and delivers infusate and contrast (4:1) into the adventitia $(103,104)$.

After a preliminary first in human trial, the DANCE trial was performed. DANCE was a multi-center study with 262 subjects (283 limbs) (NCT01983449) (103,104). Patients were treated with either atherectomy $(\mathrm{n}=159)$ or BA $(n=124)$ combined with dexamethasone adventitial infusion, at a dosage of $1.6 \mathrm{mg} / \mathrm{cm}$ (103). Twelve-month primary patency (defined as freedom from TLR or duplex ultrasound peak systolic velocity ratio $\leq 2.4$ ) was the primary endpoint of the study. The 12 -month KM estimates for freedom from TLR and for primary patency were $89.7 \%$ and $79.5 \%$ respectively (103).

The LIMBO trials are two multi-center, prospective, randomized trials that are enrolling patients in Europe (NCT02479555) and the USA (NCT02479620) to test dexamethasone administration $(4 \mathrm{mg} / \mathrm{mL})$ with PTA and atherectomy respectively. Each trial will include up to 120 patients (60 treated with dexamethasone and 60 controls). The estimated completion date is in 2020 . The Temsirolimus Adventitial Delivery to Improve Angiographic Outcomes Below the Knee (TANGO) trial is a Phase 2, multi-center, prospective, randomized, blinded dose escalation study with perivascular drug delivery that pairs the Bullfrog ${ }^{\circledR}$ Micro-Infusion Device with TORISEL ${ }^{\circledR}$ (temsirolimus) to treat IP arteries after revascularization. TANGO was conducted in 7 centers in the US (NCT02908035) and enrolled 60 patients in total (20 low-dose, 20 high-dose and 20 controls). Temsirolimus is an analogue of sirolimus that has already been shown to prevent restenosis after percutaneous coronary intervention and contrary to paclitaxel will mainly apply its effect by reducing cellular proliferation in order to limit restenosis.

\section{Post-angioplasty dissections}

Post-BA dissections present as longitudinal tears or flow disturbance in the vessel wall that are visible on angiography (105-107). Dissection in peripheral interventions with BA occur in more than $50 \%$ of cases and increase exponentially 
the risk of TLR, while specifically dissection type C-E increase the TLR risk even more compared to A-B and almost four times compared to lesions treated successfully without dissections (106-108). The dissection flap is usually treated with the placement of a stent which can increase the risk for restenosis or even stent fracture $(109,110)$.

The Tack Implant (Intact Vascular, Inc., Wayne, Pennsylvania) has length of $6 \mathrm{~mm}$ and an open lattice design, has $81 \%$ less total metal surface and avoids some disadvantages of stents but can still be implanted, maintain scaffolding and potentiate the opposition of the dissection flaps (111). The TOBA I trial studied the use of the Tack Implant device and showed that device implantation was successful in the vast majority of the cases (128/130) with bail-out stenting needed in only two patients $(111,112)$. After 1 year of follow-up, the KM estimates for freedom from MAE, TLR and loss of primary patency were $88 \%$, $89.5 \%$ and $76.4 \%(111,112)$.

The Tack Optimized Balloon Angioplasty (TOBA) II study was conducted in multiple US and European centers to test the Tack device for post-angioplasty FP dissections (NCT02522884). TOBA II enrolled in total 213 patients (almost 70\% with severe dissections) and achieved a 92\% resolution of the dissections. The 12-month KM estimates for freedom from TLR and for primary patency were $86.5 \%$ and $79.3 \%$ respectively. There were zero device fractures, almost no device migration and the bail-out stenting rate was $0.5 \%$.

TOBA BTK is a single arm, prospective study that enrolled patients with IP lesions (NCT02235675) in more than 40 sites in Europe and the US in order to examine the effectiveness and safety of the Tack device for the repair of post-BA dissections in the distal part of popliteal artery or IP arteries (113). Contrary to the way that the Tack endovascular system is structured for above the knee arteries (six self-expanding nitinol devices), the IP device has four self-expanding nitinol stents. In total, 32 out of 35 patients (91.4\%) had post-BA dissection and successful deployment of the Tack. Procedural success was achieved in all but one case $(97.1 \%)$. There were no 30 -day MALE, while the 12 -month patency rate was $78.4 \%$ and the 12 -month freedom from clinically driven TLR was $93.5 \%$ (113). The investigators concluded that the use of the Tack implant for the treatment of post BA dissection was safe and effective with low TLR and reasonable 12-month patency rates in IP lesions (113). The TOBA II BTK study (NCT02942966) is a multicenter study examining the effectiveness of the Tack device for IP disease. Enrollment is complete and results will be reported at the end of 2019 .

Finally the TOBA III study, which is a multicenter, single-arm, prospective study examined the combination of the Tack implant with Medtronic's IN.PACT Admiral DCB for SFA and/or proximal popliteal arteries. The results were presented at TCT 2019. The study was conducted in Europe and included a total of 201 patients including 169 patients with lesions between 20 and $150 \mathrm{~mm}$ and a subgroup of 322 patients with lesions between 150 and $250 \mathrm{~mm}$ (NCT02802306). The results were presented at TCT 2019. The standard lesion cohort $(\leq 150 \mathrm{~mm})$ demonstrated $97.7 \%$ complete dissection resolution and the KM estimates for 12 -month vessel patency and freedom from TLR were $95 \%$ and 97.5 respectively, while the bail-out stenting rate was 0.6. Among the long dataset, there was a $98.8 \%$ complete dissection resolution, while the 12 -month $\mathrm{KM}$ estimates for vessel patency and freedom from TLR were $89.3 \%$ and $96.8 \%$ respectively. The bail-out stenting rate was 0 .

\section{Intravascular lithotripsy}

Medial calcification is associated with age, diabetes and other cardiovascular risk factors in patients with PAD (114-116). Vessel calcification can be an obstacle for wire crossing, balloon dilation, stent deployment and absorption of paclitaxel, while increasing the risk of stent fracture, procedural complications and leads to worse outcomes (117-122). As a result, calcified vessels have been excluded from most of the randomized trials. Atherectomy devices have for years provided a method for treatment of calcified vessels in patients with PAD in order to prepare the vessel for balloon angioplasty and adequate stent expansion (123).

\section{Novel treatments for peripheral calcification- intravascular lithotripsy}

The Shockwave Lithoplasty ${ }^{\circledR}$ System (Shockwave Medical, Fremont, CA, USA) is a proprietary lithotripsy-enhanced balloon catheter that consists of a balloon catheter platform $6 \mathrm{~cm}$ in length and diameter ranging from 3.5 to $7 \mathrm{~mm}$ with multiple integrated lithotripsy electrodes, and a generator (124-127). The Shockwave system is designed to be delivered through the peripheral arterial system of the lower extremities to the site of calcified stenosis. When the lithotripsy function is activated, it generates mechanical energy within the target segment that can disrupt the calcium in the lesion. The Shockwave system is designed to use low inflation pressures in order to potentially minimize 
vascular injury. The lithotripsy connector delivers energy from the generator to the lithotripsy electrodes located on the center shaft of the balloon. A total of 30 impulses are delivered per treatment cycle, at least 2 lithoplasty cycles are delivered per lesion segment, and the catheter expires after 10 treatment cycles and 300 shocks. Similarly to the treatment of renal calculi, the principle of intravascular lithotripsy is that the use of pulsatile sonic pressure waves that pass through soft tissue and selectively interact with high-density calcium can produce significant shear stresses (124-127).

The first studies to examine the Shockwave system were the DISRUPT I and II studies. DISRUPT was a two phase, prospective, nonrandomized, multicenter that enrolled 95 patients (95 lesions) with moderately or severely calcified infrainguinal lesions $\leq 15 \mathrm{~cm}$ in length) (NCT02071108 \& NCT02369848) $(128,129)$. The average lesion length was $72 \mathrm{~mm}$, while $55 \%$ of the lesions had severe calcification. There was a $100 \%$ procedural success (defined by $<50 \%$ stenosis), no procedural complications, while predilation and postdilation were needed in $11.6 \%$ and $7.4 \%$ respectively. Bail-out stenting was needed in one lesion only (Dissection type IV). The 6-month TLR and patency were $3.2 \%$ and $76.7 \%$ respectively (129).

Lithotripsy can be used similarly to atherectomy devices, as an adjunct method for lesion preparation in order to improve BA, stent placement or even paclitaxel's absorption. A recent case series reported by Radaideh et al. reported 7 lesions treated with Shockwave. Eighty-five percent of the lesions were severely calcified (128). The Shockwave system was delivered successfully in all of them. Atherectomy was used in 2 of these cases, while there were 3 dissections (NHLBI type C) after the Shockwave treatment (130). All of the lesions were stented, while the residual stenosis was $0 \%$. The authors conclude that Shockwave lithoplasty to the iliac arteries showed excellent procedural success and no complications and full stent expansion was noted despite the high calcification rates.

DISRUPT BTK was a prospective, multicenter study with twenty subjects with the aim to examine the Shockwave device in IP lesions (NCT02911623) (124). All included patient had moderate or severe calcification in IP arteries, and 15 of them had Rutherford V. The primary safety endpoint was a composite of 30-day death, myocardial infarction, emergent target limb intervention or amputation (124), while the reduction in the diameter stenosis was defined as the primary efficacy endpoint. Shockwave was delivered successfully in all but one patients, and bail-out stenting was needed in only one case (type II dissection) (124). One hundred percent of the lesions met the primary efficacy endpoint and the average reduction in percent diameter stenosis was $46.5 \%$. There were zero $30-$ day major adverse events (primary safety endpoint).

Importantly, the use of Shockwave for iliac arteries has applications in structural heart disease also, since it can enable operators to perform transcatheter aortic valve replacement even when iliac arteries are calcified and not optimal for valve advancement (131).

The ongoing DISPUT PAD III trial is comparing the combination of Shockwave's lithotripsy with DCB vs. DCB alone with pre-dilation with conventional BA for FP lesions with moderate or severe calcification in 300 patients in Europe, the United States and New Zealand (NCT02923193) (124-126). In parallel to the randomized study, a real-world study is being conducted in order to assess lithotripsy's performance for lesions that do not meet the inclusion criteria in the RCT.

\section{Percutaneous bypass}

The PQ Bypass DETOUR System (PQ Bypass, Inc., Silicon Valley, CA, USA) is a novel treatment approach for percutaneous femoral-popliteal bypass under fluoroscopic guidance $(132,133)$. The percutaneous FP bypass is achieved with the use of a specialized crossing device, a radiopaque snare, and the Torus stent graft (132). A number of proprietary TORUS Stent Grafts are deployed in a continues and overlapping fashion from the popliteal artery into the femoral vein and from the femoral vein into the SFA through two independent anastomoses in order to create a endovascular bypass from the SFA to the popliteal artery (134). The rationale behind PQ Bypass is based on the fact that there are limited treatment choices for patients with long FP lesions, since endovascular techniques are associated with high TLR and low patency rates, while surgical bypass is associated with lengthier admissions and high risk for procedural complication (8,135-137).

In total, in the DETOUR I study (which was a prospective single arm study in Europe, New Zealand, and Chile), there were 77 patients and 81 SFA lesions $>10 \mathrm{~cm}$ (mean length $37.1 \mathrm{~cm}$ ) included, while $96 \%$ of them were chronic total occlusions (CTOs) and almost $70 \%$ had severe calcification (133). ISR lesions were not excluded from the study. Patients were followed every $3-6$ months up to 36 months. Independent review of the data was performed by core lab adjudication at key evaluation points. The 
technical success of the study was $98.8 \%$. The 12 -month primary patency, primary assisted patency and secondary patency rates were $72.5 \%, 78 \%$ and $93.8 \%$ respectively. The 12 -month freedom from amputation was $100 \%$, while there was a $98.8 \%$ freedom from acute limb ischemia and $78.8 \%$ freedom from TLR (138). The 18-month results were announced last November at VIVA 2018 (Ehrin J Armstrong MD, Las Vegas, November 2018) (134). The 18 -month rates for primary, primary assisted and secondary patency were $67.6 \%, 78.9 \%$ and $94.1 \%$ respectively. More than $80 \%$ of the patients achieved a Rutherford 0 class by 18 months, while the mean ABI improved from 0.64 at baseline to 0.97 at 18 months. Additional data evaluating the safety and effectiveness of the Detour procedure will be collected through 36-month follow-up in the DETOUR I trial The PQ Bypass DETOUR System is currently under investigation in the US IDE DETOUR II Clinical Trial (NCT03119233) after the DETOUR I study was completed. The plan is to enroll 292 patients in US and Europe with $>15 \mathrm{~cm}$ FP lesions (134). The Detour procedure earned CE Mark approval in February 2017. The PQ Detour procedure can be a possible solution for difficult to treat long $\mathrm{FP}$ lesions which are associated with high rates of CTO, calcification and ISR and are often excluded from clinical trials, while the real-world endovascular treatment options have been consistently less durable than open bypass.

\section{Conclusions}

There is a constant evolution in the endovascular technologies and techniques used for PAD treatment. This is mirrored in the constantly improved outcomes in patients who undergo endovascular revascularization and in the expanded pool of patients who can be now treated with an endovascular approach. Despite the progress, available therapeutic choices still have limitations and newer devices have a lot of room for improved results. While further evidence is anticipated regarding the controversial role of DCBs and DES, newer drug-eluting devices are under investigation and are anticipated to enter the market in the future, including the Saval DES for IP lesions. Adventitial delivery of dexamethasone is another promising option that can potentially limit restenosis rates, while vessel preparation with Shockwave lithotripsy can improve procedural success rates for the treatment of calcified lesions. Finally, PQ bypass is a novel therapy that can potentially provide an alternative for the treatment of the long FP lesions that were so far limited by their poor outcomes when treated with an endovascular approach. Advanced phase clinical trial and large prospective realworld registries are expected to provide the peripheral interventionalists with further evidence regarding the indications and outcomes associated with the emerging endovascular technologies.

\section{Acknowledgments}

Funding: None.

\section{Footnote}

Provenance and Peer Review: This article was commissioned by the Guest Editor (Ion S. Jovin) for the series "Interventional Cardiology" published in fournal of Thoracic Disease. The article was sent for external peer review organized by the Guest Editor and the editorial office.

Conflicts of Interest: All authors have completed the ICMJE uniform disclosure form (available at http://dx.doi. org/10.21037/jtd.2019.12.130). The series "Interventional Cardiology" was commissioned by the editorial office without any funding or sponsorship. EJA is a consultant to Abbott Vascular, Boston Scientific, Cardiovascular Systems, Gore, Intact Vascular, Janssen, Medtronic, and Philips. DGK has no other conflicts of interest to declare.

Ethical Statement: The authors are accountable for all aspects of the work in ensuring that questions related to the accuracy or integrity of any part of the work are appropriately investigated and resolved.

Open Access Statement: This is an Open Access article distributed in accordance with the Creative Commons Attribution-NonCommercial-NoDerivs 4.0 International License (CC BY-NC-ND 4.0), which permits the noncommercial replication and distribution of the article with the strict proviso that no changes or edits are made and the original work is properly cited (including links to both the formal publication through the relevant DOI and the license). See: https://creativecommons.org/licenses/by-nc-nd/4.0/.

\section{References}

1. Shu J, Santulli G. Update on peripheral artery disease: epidemiology and evidence-based facts. Atherosclerosis 
2018;275:379-81.

2. Kokkinidis DG, Armstrong EJ. Emerging and Future Therapeutic Options for Femoropopliteal and Infrapopliteal Endovascular Intervention. Interv Cardiol Clin 2017;6:279-95.

3. Varu VN, Hogg ME, Kibbe MR. Critical limb ischemia. J Vasc Surg 2010;51:230-41.

4. Novo S, Coppola G, Milio G. Critical limb ischemia: definition and natural history. Curr Drug Targets Cardiovasc Haematol Disord 2004;4:219-25.

5. Olin JW, Allie DE, Belkin M, et al. ACCF/AHA/ACR/ SCAI/SIR/SVM/SVN/SVS 2010 Performance Measures for Adults With Peripheral Artery Disease: A Report of the American College of Cardiology Foundation/ American Heart Association Task Force on Performance Measures, the American College of Radiology, the Society for Cardiac Angiography and Interventions, the Society for Interventional Radiology, the Society for Vascular Medicine, the Society for Vascular Nursing, and the Society for Vascular Surgery (Writing Committee to Develop Clinical Performance Measures for Peripheral Artery Disease) Developed in Collaboration With the American Association of Cardiovascular and Pulmonary Rehabilitation; the American Diabetes Association; the Society for Atherosclerosis Imaging and Prevention; the Society for Cardiovascular Magnetic Resonance; the Society of Cardiovascular Computed Tomography; and the PAD Coalition Endorsed by the American Academy of Podiatric Practice Management. J Am Coll Cardiol 2010;56:2147-81.

6. Kokkinidis DG, Alvandi B, Hossain P, et al. Midterm Outcomes After Endovascular Intervention for Occluded vs Stenosed External Iliac Arteries. J Endovasc Ther 2018;25:183-91.

7. Kokkinidis DG, Foley TR, Cotter R, et al. Acute and Midterm Outcomes of Antegrade vs Retrograde Crossing Strategies for Endovascular Treatment of Iliac Artery Chronic Total Occlusions. J Endovasc Ther 2019;26:342-9.

8. Kokkinidis DG, Katsaros I, Jonnalagadda AK, et al. Use, safety and effectiveness of subintimal angioplasty and reentry devices for the treatment of femoropopliteal chronic total occlusions: A systematic review of 87 studies and 4665 patients. Cardiovasc Revasc Med 2020;21:34-45.

9. Kokkinidis DG, Hossain P, Jawaid O, et al. Laser Atherectomy Combined With Drug-Coated Balloon Angioplasty Is Associated With Improved 1-Year Outcomes for Treatment of Femoropopliteal In-Stent
Restenosis. J Endovasc Ther 2018;25:81-8.

10. Agarwal S, Sud K, Shishehbor MH. Nationwide trends of hospital admission and outcomes among critical limb ischemia patients: from 2003-2011. J Am Coll Cardiol 2016;67:1901-13.

11. Sachs T, Pomposelli F, Hamdan A, et al. Trends in the national outcomes and costs for claudication and limb threatening ischemia: angioplasty vs bypass graft. J Vasc Surg 2011;54:1021-31.e1.

12. Arora S, Panaich SS, Patel N, et al. Impact of hospital volume on outcomes of lower extremity endovascular interventions (insights from the Nationwide Inpatient Sample [2006 to 2011]). Am J Cardiol 2015;116:791-800.

13. Gentile F, Lundberg G, Hultgren R. Outcome for Endovascular and Open Procedures in Infrapopliteal Lesions for Critical Limb Ischemia: Registry Based Single Center Study. Eur J Vasc Endovasc Surg 2016;52:643-9.

14. Secemsky EA, Armstrong EJ. Femoropopliteal Stent Implantation: Will Adjunctive Medical Therapy Improve Outcomes? 2018. Available online: https:// www.researchgate.net/publication/327658045_ Femoropopliteal_Stent_Implantation_Will_Adjunctive_ Medical_Therapy_Improve_Outcomes

15. Kokkinidis DG, Jeon-Slaughter H, Khalili H, et al. Adjunctive stent use during endovascular intervention to the femoropopliteal artery with drug coated balloons: Insights from the XLPAD registry. Vasc Med 2018;23:358-64.

16. Feldman DN, Armstrong EJ, Aronow HD, et al. SCAI consensus guidelines for device selection in femoralpopliteal arterial interventions. Catheter Cardiovasc Interv 2018;92:124.

17. Armstrong EJ, Waldo SW. Drug-coated balloons for long superficial femoral artery disease: leaving nothing behind in the real-world. JACC Cardiovasc Interv 2016;9:957-8.

18. Singh GD, Armstrong EJ, Laird JR. Femoropopliteal instent restenosis: current treatment strategies. J Cardiovasc Surg (Torino) 2014;55:325-33.

19. Armstrong EJ, Singh S, Singh GD, et al. Angiographic characteristics of femoropopliteal in-stent restenosis: association with long-term outcomes after endovascular intervention. Catheter Cardiovasc Interv 2013;82:1168-74.

20. Gray BH, Diaz-Sandoval LJ, Dieter RS, et al. SCAI expert consensus statement for infrapopliteal arterial intervention appropriate use. Catheter Cardiovasc Interv 2014;84:539-45.

21. Kawarada O, Fujihara M, Higashimori A, et al. Predictors of adverse clinical outcomes after successful infrapopliteal 
intervention. Catheter Cardiovasc Interv 2012;80:861-71.

22. Schmidt A, Ulrich M, Winkler B, et al. Angiographic patency and clinical outcome after balloon-angioplasty for extensive infrapopliteal arterial disease. Catheter Cardiovasc Interv 2010;76:1047-54.

23. Micari A, Cioppa A, Vadala G, et al. Clinical evaluation of a paclitaxel-eluting balloon for treatment of femoropopliteal arterial disease: 12 -month results from a multicenter Italian registry. JACC Cardiovasc Interv 2012;5:331-8.

24. Tepe G, Laird J, Schneider P, et al. Drug-coated balloon versus standard percutaneous transluminal angioplasty for the treatment of superficial femoral and popliteal peripheral artery disease: 12-month results from the IN. PACT SFA randomized trial. Circulation 2015;131:495-502.

25. Rosenfield K, Jaff MR, White CJ, et al. Trial of a paclitaxel-coated balloon for femoropopliteal artery disease. N Engl J Med 2015;373:145-53.

26. Lamichhane S, Anderson J, Remund T, Kelly P, Mani G. Dextran sulfate as a drug delivery platform for drug-coated balloons: Preparation, characterization, in vitro drug elution, and smooth muscle cell response. J Biomed Mater Res Part B Appl Biomater 2016;104:1416-30.

27. Axel DI, Kunert W, Göggelmann C, et al. Paclitaxel inhibits arterial smooth muscle cell proliferation and migration in vitro and in vivo using local drug delivery. Circulation 1997;96:636-45.

28. Zeller T, Rastan A, Macharzina R, et al. Drug-coated balloons vs. drug-eluting stents for treatment of long femoropopliteal lesions. J Endovasc Ther 2014;21:359-68.

29. Bosiers M, Deloose K, Callaert J, et al. Results of the Protégé EverFlex 200-mm-long nitinol stent (ev3) in TASC C and D femoropopliteal lesions. J Vasc Surg 2011;54:1042-50.

30. Foley TR, Cotter RP, Kokkinidis DG, et al. Mid-term outcomes of orbital atherectomy combined with drugcoated balloon angioplasty for treatment of femoropopliteal disease. Catheter Cardiovasc Interv 2017;89:1078-85.

31. Shammas NW, Shammas GA, Banerjee S, et al. JetStream rotational and aspiration atherectomy in treating in-stent restenosis of the femoropopliteal arteries: results of the JETSTREAM-ISR feasibility study. J Endovasc Ther 2016;23:339-46.

32. Cassese S, Wolf F, Ingwersen M, et al. Drug-Coated Balloon Angioplasty for Femoropopliteal In-Stent Restenosis: The REPAIR Cooperation: A Meta-Analysis of Individual Participant Data From 3 Randomized Trials.
Circ Cardiovasc Interv 2018;11:e007055.

33. Grotti S, Liistro F, Angioli P, et al. Paclitaxel-eluting balloon vs standard angioplasty to reduce restenosis in diabetic patients with in-stent restenosis of the superficial femoral and proximal popliteal arteries: three-year results of the DEBATE-ISR study. J Endovasc Ther 2016;23:52-7.

34. Kinstner CM, Lammer J, Willfort-Ehringer A, et al. Paclitaxel-eluting balloon versus standard balloon angioplasty in in-stent restenosis of the superficial femoral and proximal popliteal artery: 1-year results of the PACUBA trial. JACC Cardiovasc Interv 2016;9:1386-92.

35. Liistro F, Angioli P, Porto I, et al. Paclitaxel-eluting balloon vs. standard angioplasty to reduce recurrent restenosis in diabetic patients with in-stent restenosis of the superficial femoral and proximal popliteal arteries: the DEBATE-ISR study. J Endovasc Ther 2014;21:1-8.

36. Imran HM, Hyder ON, Soukas PA. Efficacy and safety of adjunctive drug-coated balloon therapy in endovascular treatment of common femoral artery disease. Cardiovasc Revasc Med 2019;20:210-4.

37. Stavroulakis K, Schwindt A, Torsello G, et al. Directional Atherectomy With Antirestenotic Therapy vs DrugCoated Balloon Angioplasty Alone for Isolated Popliteal Artery Lesions. J Endovasc Ther 2017;24:181-8.

38. Milnerowicz A, Milnerowicz A, Kuliczkowski W, et al. Rotational Atherectomy Plus Drug-Coated Balloon Angioplasty for the Treatment of Total In-Stent Occlusions in Iliac and Infrainguinal Arteries. J Endovasc Ther 2019;26:316-21.

39. Schmidt A, Piorkowski M, Werner M, et al. First experience with drug-eluting balloons in infrapopliteal arteries: restenosis rate and clinical outcome. J Am Coll Cardiol 2011;58:1105-9.

40. Liistro F, Porto I, Angioli P, et al. Drug-Eluting Balloon in Peripheral Intervention for Below the Knee Angioplasty Evaluation (DEBATE-BTK) A Randomized Trial in Diabetic Patients With Critical Limb Ischemia. Circulation 2013;128:615-21.

41. Fanelli F, Cannavale A, Boatta E, et al. Lower limb multilevel treatment with drug-eluting balloons: 6-month results from the DEBELLUM randomized trial. J

Endovasc Ther 2012;19:571-80.

42. Zeller T, Beschorner U, Pilger E, et al. Paclitaxel-coated balloon in infrapopliteal arteries: 12-month results from the BIOLUX P-II randomized trial (BIOTRONIK'Sfirst in man study of the Passeo-18 LUX drug releasing PTA balloon catheter vs. the uncoated Passeo-18 PTA 
balloon catheter in subjects requiring revascularization of infrapopliteal arteries). JACC Cardiovasc Interv 2015;8:1614-22 .

43. Steiner S, Schmidt A, Bausback Y, et al. Single-center experience with Lutonix drug-coated balloons in infrapopliteal arteries. J Endovasc Ther 2016;23:417-23.

44. Stone NJ, Robinson JG, Lichtenstein AH, et al. 2013 ACC/AHA guideline on the treatment of blood cholesterol to reduce atherosclerotic cardiovascular risk in adults: a report of the American College of Cardiology/American Heart Association Task Force on Practice Guidelines. J Am Coll Cardiol 2014;63:2889-934.

45. Zeller T, Baumgartner I, Scheinert D, et al. Drugeluting balloon versus standard balloon angioplasty for infrapopliteal arterial revascularization in critical limb ischemia: 12-month results from the IN. PACT DEEP randomized trial. J Am Coll Cardiol 2014;64:1568-76.

46. Katsanos K, Spiliopoulos S, Kitrou P, et al. Risk of death following application of paclitaxel-coated balloons and stents in the femoropopliteal artery of the leg: a systematic review and meta-analysis of randomized controlled trials. J Am Heart Assoc 2018;7:e011245.

47. Krawisz AK, Secemsky EA. Paclitaxel-Based Devices for the Treatment of PAD: Balancing Clinical Efficacy with Possible Risk. Curr Treat Options Cardiovasc Med 2019;21:57.

48. Shishehbor MH, Secemsky EA, Varcoe RL. Is There a Real Association Between Paclitaxel Devices and Mortality? Time to Pause and Re-Evaluate What We Know About This Statistical Finding. J Am Heart Assoc 2019;8:e012524.

49. Holden A, Varcoe RL, Jaff MR, et al. Paclitaxel and Mortality: The Dose Argument Is Critical. J Endovasc Ther 2019;26:467-70.

50. Available online: https://www.medtechdive.com/ news/uk-to-probe-safety-of-paclitaxel-cardiovasculardevices/550280/

51. Available online: https://vascularnews.com/mhra-fdaupdates-on-paclitaxel/

52. Available online: https://www.fda.gov/MedicalDevices/ Safety/LetterstoHealthCareProviders/ucm629589.htm

53. Available online: https://www.fda.gov/MedicalDevices/ Safety/LetterstoHealthCareProviders/ucm633614.htm

54. Available online: https://www.tctmd.com/news/two-trialshalted-wake-study-linking-paclitaxel-coated-devicesdeaths-pad

55. Available online: https://vascularnews.com/basil-3swedepad-trials-paused-paclitaxel/
56. Singh R, Mukhopadhyay K. Survival analysis in clinical trials: Basics and must know areas. Perspect Clin Res 2011;2:145.

57. Iida O, Soga Y, Urasawa K, et al. Drug-coated balloon vs standard percutaneous transluminal angioplasty for the treatment of atherosclerotic lesions in the superficial femoral and proximal popliteal arteries: one-year results of the MDT-2113 SFA Japan randomized trial. J Endovasc Ther 2018;25:109-17.

58. Werk M, Langner S, Reinkensmeier B, et al. Clinical perspective. Circulation 2008;118:1358-65.

59. Schneider PA, Laird JR, Tepe G, et al. Treatment effect of drug-coated balloons is durable to 3 years in the femoropopliteal arteries: long-term results of the IN. PACT SFA randomized trial. Circ Cardiovasc Interv 2018;11:e005891.

60. Schneider PA, Laird JR, Doros G, et al. Mortality Not Correlated With Paclitaxel Exposure: An Independent Patient-Level Meta-Analysis of a Drug-Coated Balloon. J Am Coll Cardiol 2019;73:2550-63.

61. Secemsky EA, Kundi H, Weinberg I, et al. Association of survival with femoropopliteal artery revascularization with drug-coated devices. JAMA Cardiol 2019;4:332-40.

62. Gray WA, Jaff MR, Parikh SA, et al. Mortality Assessment of Paclitaxel-Coated Balloons: Patient-Level MetaAnalysis of the ILLUMENATE Clinical Program at 3 Years. Circulation 2019;140:1145-55.

63. Available online: https://evtoday.com/2018/05/09/rangersfa-12-month-data-published-for-boston-scientificsranger-dcb.

64. Bausback Y, Willfort-Ehringer A, Sievert H, et al. Sixmonth results from the initial randomized study of the Ranger paclitaxel-coated balloon in the femoropopliteal segment. J Endovasc Ther 2017;24:459-67.

65. Lichtenberg M, Ranft J, Niemöller K, et al. Treatment of femoropopliteal atherosclerotic lesions using the ranger paclitaxel-coated balloon catheter: 12-month results from an all-comers registry. J Cardiovasc Surg (Torino) 2018;59:45-50.

66. Steiner S, Willfort-Ehringer A, Sievert H, et al. 12-month results from the first-in-human randomized study of the ranger paclitaxel-coated balloon for femoropopliteal treatment. JACC Cardiovasc Interv 2018;11:934-41.

67. Schillinger M, Sabeti S, Loewe C, et al. Balloon angioplasty versus implantation of nitinol stents in the superficial femoral artery. N Engl J Med 2006;354:1879-88.

68. Dick P, Wallner H, Sabeti S, et al. Balloon angioplasty 
versus stenting with nitinol stents in intermediate length superficial femoral artery lesions. Catheter Cardiovasc Interv 2009;74:1090-5.

69. Laird JR, Katzen BT, Scheinert D, et al. Nitinol stent implantation versus balloon angioplasty for lesions in the superficial femoral artery and proximal popliteal artery: twelve-month results from the RESILIENT randomized trial. Circ Cardiovasc Interv 2010;3:267-76.

70. Scheinert D, Scheinert S, Sax J, et al. Prevalence and clinical impact of stent fractures after femoropopliteal stenting. J Am Coll Cardiol 2005;45:312-5.

71. Schlager O, Dick P, Sabeti S, et al. Long-segment SFA stenting--the dark sides: in-stent restenosis, clinical deterioration, and stent fractures. J Endovasc Ther 2005;12:676-84.

72. Klein AJ, James Chen S, Messenger JC, et al. Quantitative assessment of the conformational change in the femoropopliteal artery with leg movement. Catheter Cardiovasc Interv 2009;74:787-98.

73. Laird JR. Limitations of percutaneous transluminal angioplasty and stenting for the treatment of disease of the superficial femoral and popliteal arteries. J Endovasc Ther 2006;13:II-30.

74. Yokoi H, Ohki T, Kichikawa K, et al. Zilver PTX postmarket surveillance study of paclitaxel-eluting stents for treating femoropopliteal artery disease in Japan: 12-month results. JACC Cardiovasc Interv 2016;9:271-7.

75. Dake MD, Ansel GM, Jaff MR, et al. Durable clinical effectiveness with paclitaxel-eluting stents in the femoropopliteal artery: 5-year results of the Zilver PTX randomized trial. Circulation 2016;133:1472-83.

76. Dake MD, Ansel GM, Jaff MR, et al. Sustained safety and effectiveness of paclitaxel-eluting stents for femoropopliteal lesions: 2-year follow-up from the Zilver PTX randomized and single-arm clinical studies. J Am Coll Cardiol 2013;61:2417-27.

77. Available online: https://vascularnews.com/patient-leveldata-zilver-ptx/

78. Dake MD, Ansel GM, Bosiers M, et al. Paclitaxel-Coated Zilver PTX Drug-Eluting Stent Treatment Does Not Result in Increased Long-Term All-Cause Mortality Compared to Uncoated Devices. Cardiovasc Intervent Radiol 2020;43:8-19.

79. Secemsky EA, Kundi H, Weinberg I, et al. Drug-eluting stent implantation and long-term survival following peripheral artery revascularization. J Am Coll Cardiol 2019;73:2636-8.

80. Müller-Hülsbeck S, Hopf-Jensen S, Keirse K, et al. Eluvia drug-eluting vascular stent system for the treatment of symptomatic femoropopliteal lesions. Future Cardiol 2018;14:207-13.

81. Müller-Hülsbeck S. EluviaTM peripheral stent system for the treatment of peripheral lesions above the knee. Expert Opin Drug Deliv 2016;13:1639-44.

82. Hou D, Huibregtse BA, Eppihimer M, et al.

Fluorocopolymer-coated nitinol self-expanding paclitaxeleluting stent: pharmacokinetics and vascular biology responses in a porcine iliofemoral model. EuroIntervention 2016;12:790-7.

83. Gasior P, Cheng Y, Valencia AF, et al. Impact of fluoropolymer-based paclitaxel delivery on neointimal proliferation and vascular healing: a comparative peripheral drug-eluting stent study in the familial hypercholesterolemic swine model of femoral restenosis. Circ Cardiovasc Interv 2017;10:e004450.

84. Müller-Hülsbeck S, Keirse K, Zeller T, et al. Twelvemonth results from the MAJESTIC trial of the Eluvia paclitaxel-eluting stent for treatment of obstructive femoropopliteal disease. J Endovasc Ther 2016;23:701-7.

85. Gray WA, Keirse K, Soga Y, et al. A polymer-coated, paclitaxel-eluting stent (Eluvia) versus a polymer-free, paclitaxel-coated stent (Zilver PTX) for endovascular femoropopliteal intervention (IMPERIAL): a randomised, non-inferiority trial. Lancet 2018;392:1541-51.

86. Conrad MF, Crawford RS, Hackney LA, et al. Endovascular management of patients with critical limb ischemia. J Vasc Surg 2011;53:1020-5.

87. Gandini R, Volpi T, Pampana E, et al. Applicability and clinical results of percutaneous transluminal angioplasty with a novel, long, conically shaped balloon dedicated for below-the knee interventions. J Cardiovasc Surg (Torino) 2009;50:365-71.

88. Mustapha JA, Finton SM, Diaz-Sandoval LJ, et al. Percutaneous transluminal angioplasty in patients with infrapopliteal arterial disease: systematic review and metaanalysis. Circ Cardiovasc Interv 2016;9:e003468.

89. Bosiers M, Scheinert D, Peeters P, et al. Randomized comparison of everolimus-eluting versus bare-metal stents in patients with critical limb ischemia and infrapopliteal arterial occlusive disease. J Vasc Surg 2012;55:390-8.

90. Spreen MI, Martens JM, Hansen BE, et al. Percutaneous transluminal angioplasty and drug-eluting stents for infrapopliteal lesions in critical limb ischemia (PADI) trial. Circ Cardiovasc Interv 2016;9:e002376.

91. Scheinert D, Katsanos K, Zeller T, et al. A prospective randomized multicenter comparison of balloon angioplasty 
and infrapopliteal stenting with the sirolimus-eluting stent in patients with ischemic peripheral arterial disease: 1 -year results from the ACHILLES trial. J Am Coll Cardiol 2012;60:2290-5.

92. Spiliopoulos S, Theodosiadou V, Katsanos K, et al. LongTerm Clinical Outcomes of Infrapopliteal Drug-Eluting Stent Placement for Critical Limb Ischemia in Diabetic Patients. J Vasc Interv Radiol 2015;26:1423-30.

93. Fusaro M, Cassese S, Ndrepepa G, et al. Drug-eluting stents for revascularization of infrapopliteal arteries: updated meta-analysis of randomized trials. JACC Cardiovasc Interv 2013;6:1284-93.

94. Rastan A, Brechtel K, Krankenberg H, et al. Sirolimuseluting stents for treatment of infrapopliteal arteries reduce clinical event rate compared to bare-metal stents: long-term results from a randomized trial. J Am Coll Cardiol 2012;60:587-91.

95. Siablis D, Kitrou PM, Spiliopoulos S, et al. Paclitaxelcoated balloon angioplasty versus drug-eluting stenting for the treatment of infrapopliteal long-segment arterial occlusive disease: the IDEAS randomized controlled trial. JACC Cardiovasc Interv 2014;7:1048-56.

96. Available online: https://evtoday.com/2019/05/ supplement/the-saval-trial/

97. Wilcox JN, Waksman R, King SB, et al. The role of the adventitia in the arterial response to angioplasty: the effect of intravascular radiation. Int J Radiat Oncol Biol Phys 1996;36:789-96.

98. Scott NA, Cipolla GD, Ross CE, et al. Identification of a potential role for the adventitia in vascular lesion formation after balloon overstretch injury of porcine coronary arteries. Circulation 1996;93:2178-87.

99. Siow RCM, Mallawaarachchi CM, Weissberg PL. Migration of adventitial myofibroblasts following vascular balloon injury: insights from in vivo gene transfer to rat carotid arteries. Cardiovasc Res 2003;59:212-21.

100. Okamoto E, Couse T, De Leon H, et al. Perivascular inflammation after balloon angioplasty of porcine coronary arteries. Circulation 2001;104:2228-35.

101. Maiellaro K, Taylor WR. The role of the adventitia in vascular inflammation. Cardiovasc Res 2007;75:640-8.

102.Hu Y, Xu Q. Adventitial biology: differentiation and function. Arterioscler Thromb Vasc Biol 2011;31:1523-9.

103. Razavi MK, Donohoe D, D'Agostino RB Jr, et al. Adventitial drug delivery of dexamethasone to improve primary patency in the treatment of superficial femoral and popliteal artery disease: 12 -month results from the DANCE clinical trial. JACC Cardiovasc Interv
2018;11:921-31.

104.Owens CD, Gasper WJ, Walker JP, et al. Safety and feasibility of adjunctive dexamethasone infusion into the adventitia of the femoropopliteal artery following endovascular revascularization. J Vasc Surg 2014;59:1016-24.

105. Fischman DL, Savage MP, Leon MB, et al. Effect of intracoronary stenting on intimal dissection after balloon angioplasty: results of quantitative and qualitative coronary analysis. J Am Coll Cardiol 1991;18:1445-51.

106. Tepe G, Zeller T, Schnorr B, et al. High-grade, nonflow-limiting dissections do not negatively impact longterm outcome after paclitaxel-coated balloon angioplasty: an additional analysis from the THUNDER study. J Endovasc Ther 2013;20:792-800.

107. Werk M, Albrecht T, Meyer DR, et al. Paclitaxelcoated balloons reduce restenosis after femoro-popliteal angioplasty: evidence from the randomized PACIFIER trial. Circ Cardiovasc Interv 2012;5:831-40.

108. Tepe G, Zeller T, Albrecht T, et al. Local delivery of paclitaxel to inhibit restenosis during angioplasty of the leg. N Engl J Med 2008;358:689-99.

109. Tosaka A, Soga Y, Iida O, et al. Classification and clinical impact of restenosis after femoropopliteal stenting. J Am Coll Cardiol 2012;59:16-23.

110. Kiguchi MM, Marone LK, Chaer RA, et al. Patterns of femoropopliteal recurrence after routine and selective stenting endoluminal therapy. J Vasc Surg 2013;57:37-43.

111. Schneider PA, Giasolli R, Ebner A, et al. Early experimental and clinical experience with a focal implant for lower extremity post-angioplasty dissection. JACC Cardiovasc Interv 2015;8:347-54.

112. Bosiers M, Scheinert D, Hendriks JMH, et al. Results from the Tack Optimized Balloon Angioplasty (TOBA) study demonstrate the benefits of minimal metal implants for dissection repair after angioplasty. J Vasc Surg 2016;64:109-16.

113. Brodmann M, Wissgott C, Holden A, et al. Treatment of infrapopliteal post-PTA dissection with tack implants: 12-month results from the TOBA-BTK study. Catheter Cardiovasc Interv 2018;92:96-105.

114. David Smith C, Bilmen JG, Iqbal S, et al. Medial artery calcification as an indicator of diabetic peripheral vascular disease. Foot ankle Int 2008;29:185-90.

115.Bishop PD, Feiten LE, Ouriel K, et al. Arterial calcification increases in distal arteries in patients with peripheral arterial disease. Ann Vasc Surg 2008;22:799-805. 
116.Pohle K, Mäffert R, Ropers D, et al. Progression of aortic valve calcification: association with coronary atherosclerosis and cardiovascular risk factors. Circulation 2001;104:1927-32.

117. Rennenberg RJ, Kessels AGH, Schurgers LJ, et al. Vascular calcifications as a marker of increased cardiovascular risk: a meta-analysis. Vasc Health Risk Manag 2009;5:185.

118.Huang CL, Wu IH, Wu YW, et al. Association of lower extremity arterial calcification with amputation and mortality in patients with symptomatic peripheral artery disease. PLoS One 2014;9:e90201.

119.Spaargaren GJ, Lee MJ, Reekers JA, et al. Evaluation of a new balloon catheter for difficult calcified lesions in infrainguinal arterial disease: outcome of a multicenter registry. Cardiovasc Intervent Radiol 2009;32:132-5.

120.Shammas NW, Coiner D, Shammas G, et al. Predictors of provisional stenting in patients undergoing lower extremity arterial interventions. Int J Angiol 2011;20:95-100.

121. Cheng CP, Choi G, Herfkens RJ, et al. The effect of aging on deformations of the superficial femoral artery resulting from hip and knee flexion: potential clinical implications. J Vasc Interv Radiol 2010;21:195-202.

122. Otsuka Y, Kasahara Y, Kawamura A. Use of SafeCut Balloon for treatment of in-stent restenosis of a previously underexpanded sirolimus-eluting stent with a heavily calcified plaque. J Invasive Cardiol 2007;19:E359-62.

123. Feldman DN. Atherectomy for calcified femoropopliteal disease: are we making progress. J Invasive Cardiol 2014;26:304-6.

124. Brodmann M, Holden A, Zeller T. Safety and feasibility of intravascular lithotripsy for treatment of below-the-knee arterial stenoses. J Endovasc Ther 2018;25:499-503.

125.Brodmann M, Werner M, Holden A, et al. Primary outcomes and mechanism of action of intravascular lithotripsy in calcified, femoropopliteal lesions: Results of Disrupt PAD II. Catheter Cardiovasc Interv 2019;93:335-42.

126.Brodmann M, Werner M, Brinton TJ, et al. Safety and performance of lithoplasty for treatment of calcified peripheral artery lesions. J Am Coll Cardiol
2017;70:908-10.

127.Zeller T. Impact of lithoplasty: Disrupt PAD. Abstract presented at: VIVA 2016; September 18-22, 2016; Las Vegas, NV, USA. In: Las Vegas; 2016.

128. Available online: https://evtoday.com/2016/04/28/disruptpad-study-results-presented-for-shockwave-medicalslithoplasty-system

129. Brinton T, Brodmann M, Werner M, et al. TCT-777 Safety and Performance of the Shockwave Medical Lithoplasty® System in treating calcified peripheral vascular lesions: 6-Month Results from the two-phase DISRUPT PAD Study. J Am Coll Cardiol 2016;68:B314.

130.Available online: https://www.vasculardiseasemanagement. com/content/safety-and-efficacy-lithoplasty-treatingseverely-calcified-iliac-arterial-disease-single

131. Di Mario C, Goodwin M, Ristalli F, et al. A Prospective Registry of Intravascular Lithotripsy-Enabled Vascular Access for Transfemoral Transcatheter Aortic Valve Replacement. JACC Cardiovasc Interv 2019;12:502.

132. Krievins D, Savlovskis J, Ezite N, et al. The DETOUR procedure: no more need for conventional bypass surgery? J Cardiovasc Surg (Torino) 2018;59:172-7.

133. Available online: https://evtoday.com/2018/06/28/twelvemonth-data-presented-for-pq-bypass-detour-system

134. Late-Breaking Clinical Trials. Presented at: VIVA 18; Nov. 5-8, 2018; Las Vegas. In: Las Vegas; 2018.

135. Scheinert D, Laird Jr JR, Schröder M, et al. Excimer laserassisted recanalization of long, chronic superficial femoral artery occlusions. J Endovasc Ther 2001;8:156-66.

136.Ko YG, Kim JS, Choi DH, et al. Improved technical success and midterm patency with subintimal angioplasty compared to intraluminal angioplasty in long femoropopliteal occlusions. J Endovasc Ther 2007;14:374-81.

137.London NJM, Srinivasan R, Naylor AR, et al. Subintimal angioplasty of femoropopliteal artery occlusions: the longterm results. Eur J Vasc Surg 1994;8:148-55.

138. Krievins D, et al. S8: Scientific Session 8. Presented at: Society for Vascular Surgery Vascular Annual Meeting; June 20-23, 2018; Boston.
Cite this article as: Kokkinidis DG, Armstrong EJ. Current developments in endovascular therapy of peripheral vascular disease. J Thorac Dis 2020;12(4):1681-1694. doi: 10.21037/ jtd.2019.12.130 